Article

\title{
Study on the Effect and Mechanism of Alkali-Silica Reaction Expansion in Glass Concrete
}

\author{
Da Huang ${ }^{1,2}$, Pengliang Sun ${ }^{3}$, Pengfei Gao ${ }^{1,2}$, Guangyan Liu ${ }^{1,2, *}$, Yuanhao Wang ${ }^{1,2, *}$ and Xuandong Chen ${ }^{1,2}$ \\ 1 Guangxi Key Laboratory of New Energy and Building Energy Saving, Guilin 541004, China; \\ Huangda@ppsuc-edu.cn (D.H.); Gaopf@ppsuc-edu.cn (P.G.); Chenxuan-dong@ppsuc-edu.cn (X.C.) \\ 2 College of Civil and Architecture Engineering, Guilin University of Technology, Guilin 541004, China \\ 3 School of Chemical Science and Technology, Yunnan University, Kunming 650091, China; \\ Sunpengliang29@163.com \\ * Correspondence: liugyan@yeah.net (G.L.); gxwangyuanhao@gmail.com (Y.W.)
}

Citation: Huang, D.; Sun, P.; Gao, P.; Liu, G.; Wang, Y.; Chen, X. Study on the Effect and Mechanism of Alkali-Silica Reaction Expansion in Glass Concrete. Sustainability 2021, 13, 10618. https://doi.org/10.3390/ su131910618

Academic Editors: Tian You, Zongwei Han and Yang Zhao

Received: 11 June 2021

Accepted: 13 September 2021

Published: 24 September 2021

Publisher's Note: MDPI stays neutral with regard to jurisdictional claims in published maps and institutional affiliations.

Copyright: (c) 2021 by the authors. Licensee MDPI, Basel, Switzerland. This article is an open access article distributed under the terms and conditions of the Creative Commons Attribution (CC BY) license (https:/ / creativecommons.org/licenses/by/ $4.0 /)$.

\begin{abstract}
The suppression of ASR expansion hazards of glass concrete has always been a key and hot issue in the research of glass concrete. According to the ASTM C1260-14 fast mortar rod method, glass sand and glass powder act as fine aggregate and auxiliary cementing material, respectively. The changes in expansion rate with different amounts of glass sand content and different particle sizes of glass powder in mortar rods were compared, and the effects of glass sand content and the glass powder particle size on the expansion of ASR were analyzed. SEM was used to compare and analyze the microstructure of mortar rods to explore the mechanism of ASR expansion of glass concrete, and the results showed that the addition of glass powder had a certain inhibitory effect on ASR expansion. The larger the particle size of glass powder was, the better the inhibition effect on ASR expansion and the longer its duration. Compared with the three groups of experiments of $0-13 \mu \mathrm{m}, 13-38 \mu \mathrm{m}$, and 38-75 $\mu \mathrm{m}$, it was found that the influence of the glass powder particle size on the expansion of ASR was weaker than that of dosage. The inhibitory effect of glass powder on ASR expansion is related to the fact that glass powder is more involved in pozzolanic reaction in the early hydration process.
\end{abstract}

Keywords: glass; concrete; ASR expansion; CSH gel; mechanism

\section{Introduction}

With the continuous development of industrialization and urbanization in various countries, glass is widely used in various fields of production and life but is followed by a sharp increase in waste glass. The production of waste glass in the world has been increasing at an astonishing rate nowadays, becoming an important source of environmental pollution. However, using waste glass in building materials is a more effective way of making use of waste glass, which can reduce solid waste and save building material resources.

At present, the research on waste glass concrete, on both national and international levels, is mainly divided into the following parts: In the first group of studies, the ground glass is used as concrete fine aggregate [1-5], while in the second, it is used as inert filling material in concrete [6,7]; the third theme of research is to produce cement as cement clinker, and in the fourth, cement is partially replaced as an auxiliary cementitious material [8-10]. It is found that when waste glass is used as aggregate, the mechanical properties of concrete are reduced, mainly due to the existence of a weak interface [11,12]. In addition, an alkaliaggregate reaction will occur when the aggregate particles are larger (mainly refers to the particle size larger than 1.2 1.5 mm), which leads to the expansion failure of concrete by water absorption $[11,12]$. This phenomenon does not occur when the glass is ground into powder, but the potentially high alkali content caused by it must be noted. Glass has a pozzolanic activity after being ground into powder, which is also a much debated problem among researchers [13-15]. 
At first, a large number of researchers mainly devoted themselves to the study of waste glass in concrete aggregate for a long time [3-5]. Due to the alkali in cement and a large amount of active silica in glass, which leads to considerable alkali-aggregate reaction and expansion damage of concrete [10] and thus has made the research stagnant. Although researchers have proposed several methods to reduce ASR expansion, such as replacing the original cement with pozzolanic cement, adding fiber materials to waste glass concrete, adding lithium compounds, etc. [16], the outcomeis still not satisfactory. Some researchers also used glass as the raw material for the production of cement. However, the experiments showed that the increase in alkali content in cement after the addition of glass addition easily causesan alkali-aggregate reaction, which is not beneficial to the performance of concrete [17]. Mohajerani et al. proved that when the glass powder is ground to a certain extent, it does not cause ASR, and it also has pozzolanic activity, which can improve the performance of concrete [16]. Researchers found that when the particle size of glass powder is less than $300 \mu \mathrm{m}$, it shows significant pozzolanic activity, and the ASR reaction will become very weak [18]. Meyer et al. found that when the cement replacement rate is low and the age is 90 days, the pozzolanic activity of glass powder is higher than that of fly ash when the sizeis less than $100 \mu \mathrm{m}$ [19]. Jani et al. proved that glass powder has good pozzolanic activity when the particle size is less than $20 \mu \mathrm{m}$. The activity indices of $7 \mathrm{~d}, 28 \mathrm{~d}$, and $90 \mathrm{~d}$ reach $82 \%, 95 \%$, and 102\% [20], respectively. Schwarz et al. found that when the waste glass powder is added into concrete, the compressive strength of concrete is the best, and the hydration effect is enhanced when the content is $10 \%$ [21].

However, an earlier study found [22-24] that glass concrete was prone to alkali-silicic acid reaction (ASR), resulting in local expansion and cracking of the concrete, which severelyaffected the safety of concrete structures. This is the most important factor restricting the development and application of waste glass concrete. Therefore, the suppression of the ASR expansion hazards of glass concrete has always been a key and hot issue in glass concrete research. At present, the main measures to inhibit the expansion of glass concrete ASR include the mixing of fly ash, metakaolin, slag, silica fume, and other mineral admixtures [25-29], mixing chemical admixtures such as lithium-containing compounds and aluminum-containing compounds [30-34], controlling the size of glass particles [35-38], etc. Interestingly, many scholars have shown [39-41] that ground glass powder itself is an effective ASR expansion inhibitor. As an auxiliary cementitious material for concrete, glass grinding can stimulate the activity of volcanic ash, helping to improve the mechanical properties and durability of concrete and reduce the ASR hazards of glass concrete.

In this paper, according to ASTM C1260-14 "Standard Test Method for Alkali Potential Reactivity of Aggregate. Cement Stick Method", the ASTM C1260 rapid mortar bar method was adopted [42]. The glass sand and glass powder prepared by waste glass were used as aggregate and auxiliary cementitious materials, respectively. The river sand and cement were replaced by equal mass, the expansion rate of mortar rods with a different glass sand content and different particle size of glass powder was compared, and the effects of glass sand content and particle size of glass powder on ASR expansion were analyzed. The microstructure of mortar bars was analyzed by scanning electron microscopy (SEM), to further explore the mechanism of glass sand content and glass powder particle size on ASR expansion of glass concrete. The inhibition mechanism of glass powder on ASR expansion may be due to the potential pozzolanic property of ground glass powder. Glass powder is mixed into concrete as auxiliary cementitious material to provide relevant theoretical support for the recycling and reuse of waste glass in concrete.

\section{Experiment}

\subsection{Raw Materials}

The experimental cement is P.O. 42.5 ordinary Portland cement produced by Guilin Conch cement Factory, its specific surface area is $420.9 \mathrm{~m}^{2} / \mathrm{Kg}$, density is $3150 \mathrm{~kg} / \mathrm{m}^{3}$. The main chemical composition is shown in Table 1. The sand used in the experiment is the Lijiang River sand collected locally in Guilin; its apparent density is $2630 \mathrm{~kg} / \mathrm{m}^{3}$. ASTM 
C1260-01 "Standard Test Method for Alkali Potential Reactivity of Aggregate. Mortar Stick Method" and TB/T 2922.5-2010 "Rapid Mortar Rod Method for Testing Alkaline Reactivity of Aggregate for Railway Concrete" were screened, to obtain the river sand particles with different grain sizes, and then the experimental sand was prepared according to the gradation shown in the specification. The glass was made of brown beer bottles recycled from the local waste station in Guilin. $\mathrm{NaOH}$ using alkali with purity $\geq 98 \%$ was purchased from Tiantian instrument and equipment Co., Ltd. (Guilin, China).

Table 1. Chemical compositions of cement and glass (wt. \%).

\begin{tabular}{ccccccccccc}
\hline Compositions & $\mathrm{SiO}_{2}$ & $\mathrm{Al}_{\mathbf{2}} \mathbf{O}_{\mathbf{3}}$ & $\mathrm{CaO}$ & $\mathrm{Na}_{\mathbf{2}} \mathbf{O}$ & $\mathbf{K}_{\mathbf{2}} \mathbf{O}$ & $\mathrm{Fe}_{\mathbf{2}} \mathbf{O}_{\mathbf{3}}$ & $\mathbf{M g O}$ & $\mathrm{SO}_{3}$ & $\mathrm{TiO}_{2}$ & $\mathbf{O t h e r}$ \\
\hline Cement & 20.2 & 4.7 & 61.9 & 0.19 & 0.82 & 3.0 & 2.6 & 3.9 & $/$ & 1.9 \\
Glass power & 72.2 & 2.55 & 7.11 & 0.42 & 0.64 & 2.47 & 0.46 & $/$ & 0.15 & 1.03 \\
\hline
\end{tabular}

\subsection{Preparation of Glass Powder with Different Particle Sizes}

The initial diameter range of glass sand from waste glass products purchased from a waste recycling station was mainly $233-282 \mu \mathrm{m}$. The specific surface area was $365.7 \mathrm{~m}^{2} / \mathrm{kg}$, and the density was $2470 \mathrm{~kg} / \mathrm{m}^{3}$. The main chemical components are shown in Table 1 . The final particle size of glass powder was $0-13 \mu \mathrm{m}, 13-38 \mu \mathrm{m}$, and $38-75 \mu \mathrm{m}$ by cleaning, crushing, ball milling, screening, and drying. The preparation process is shown in Figure 1. The specific surface area and density of each particle size of glass powder are shown in Table 2.

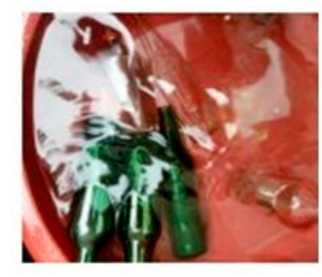

(a)Cleaning

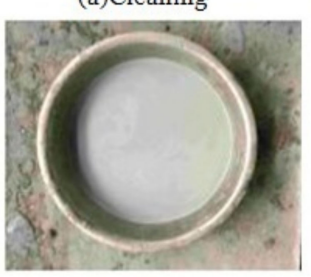

(e)Dissolving into water

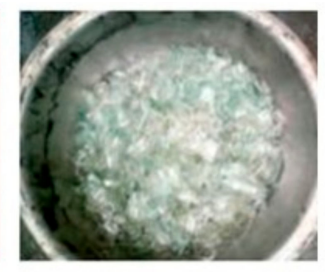

(b)Preliminary crushing

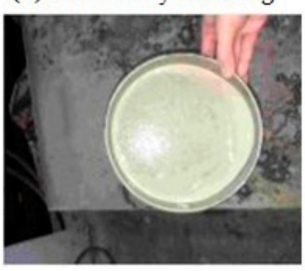

(f)Screening by Wet sieve method

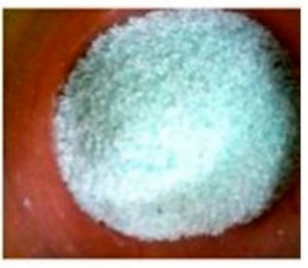

(c)Jaw crushing

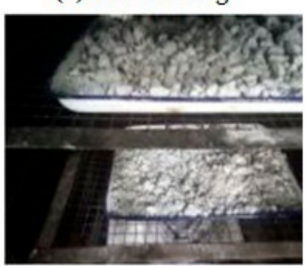

(g)Drying

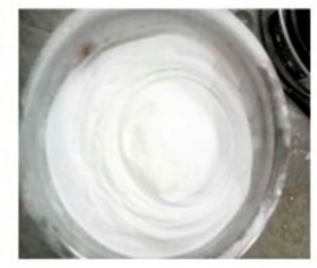

(d)Ball-milledinto powder

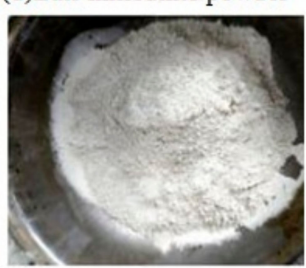

(h)Secondary Ball-milled

Figure 1. Flowcharts for preparation of glass powder with different particle sizes. (a) Cleaning; (b) Preliminary crushing; (c) Jaw crushing; (d) Ball-milledinto powder; (e) Dissolving into water; (f) Screening by Wet sieve method; (g) Drying; (h) Secondary Ball-milled.

Table 2. Blaine surface area and density of glass power with different particle sizes.

\begin{tabular}{ccc}
\hline Particle Size $(\boldsymbol{\mu m})$ & Blaine Surface Area $\left(\mathbf{m}^{\mathbf{2}} \mathbf{/ k g}\right)$ & Density $\left(\mathbf{k g} / \mathbf{m}^{\mathbf{3}}\right)$ \\
\hline $0-13$ & 729.0 & 2510 \\
$13-38$ & 521.8 & 2490 \\
$38-75$ & 441.2 & 2480 \\
\hline
\end{tabular}




\subsection{Experimental Method}

Glass powder and glass sand were used as auxiliary cementing material and aggregate, respectively, to replace cement and river sand with equal mass. According to the mixture ratio shown in Table 3, mortar bar specimens were made, and the specimen size was $25 \mathrm{~mm} \times 25 \mathrm{~mm} \times 280 \mathrm{~mm}$. A total of 12 sets of mortar rod specimens were made in this experiment, with 3 specimens in each group. Among them, JZ0, JZ20, and JZ100 were the control specimens without glass powder and glass sand content $(0 \%, 20 \%, 100 \%)$. The molds of each group were removed after pouring for $24 \mathrm{~h}$. The initial length of the mortar bar was measured at room temperature and then placed in a $1.0 \mathrm{~mol} / \mathrm{L} \mathrm{NaOH}$ curing solution in a constant temperature water bath. The temperature was maintained at $80^{\circ} \mathrm{C}$ \pm 1 . The lengths of mortar rods at $14 \mathrm{~d}$ were tested. The specimen was taken out of the thermostat, and the length test of the mortar bar was completed within $15 \mathrm{~s}$ to reduce the influence of ambient temperature on the test results. The length of each mortar bar at different ages was measured, and the expansion rate of each specimen at different ages was calculated by Equation (1); then, the final expansion rate of each group was obtained. The microstructure and reaction product composition of specimens after curing for $14 \mathrm{~d}$ were observed by scanning electron microscopy (SEM), and the effect and mechanism of ASR expansion of glass concrete were analyzed.

$$
\varepsilon_{\mathrm{t}}=\frac{\mathrm{L}_{\mathrm{t}}-\mathrm{L}_{0}}{\mathrm{~L}_{0}-2 \Delta} \times 100 \%
$$

where $\varepsilon_{t}$ is the expansion rate of the test piece on day $t ; L_{t}$ is the length of the test piece on day $t ; L_{0}$ is the initial length of the test piece; $\Delta$ is the length of the test probe.

Table 3. Mix proportion of the sample.

\begin{tabular}{|c|c|c|c|c|c|c|c|c|}
\hline Number & $\begin{array}{c}\text { Glass Powder } \\
\text { Particle Size } \\
/ \mu \mathrm{m}\end{array}$ & $\begin{array}{l}\text { Glasspowdercontent } \\
\text { /wt. } \%\end{array}$ & $\begin{array}{c}\text { Glass Sand } \\
\text { Content } \\
\text { /wt. } \%\end{array}$ & $\begin{array}{l}\text { Cement } \\
/ \mathrm{g}\end{array}$ & $\begin{array}{c}\text { Glass } \\
\text { Powder/g }\end{array}$ & $\begin{array}{c}\text { Glass } \\
\text { Sand } \\
/ g\end{array}$ & $\begin{array}{l}\text { Sand } \\
/ g\end{array}$ & $\begin{array}{l}\text { Water } \\
/ \mathrm{mL}\end{array}$ \\
\hline JZ0 & / & 0 & 0 & 400 & 0 & 0 & 900 & 188 \\
\hline GP1 & $0 \sim 13$ & 20 & 0 & 320 & 80 & 0 & 900 & 188 \\
\hline GP2 & $13 \sim 38$ & 20 & 0 & 320 & 80 & 0 & 900 & 188 \\
\hline GP3 & $38 \sim 75$ & 20 & 0 & 320 & 80 & 0 & 900 & 188 \\
\hline JZ20 & / & 0 & 20 & 400 & 0 & 180 & 720 & 188 \\
\hline GP4 & $0 \sim 13$ & 20 & 20 & 320 & 80 & 180 & 720 & 188 \\
\hline GP5 & $13 \sim 38$ & 20 & 20 & 320 & 80 & 180 & 720 & 188 \\
\hline GP6 & $38 \sim 75$ & 20 & 20 & 320 & 80 & 180 & 720 & 188 \\
\hline JZ100 & / & 0 & 100 & 400 & 0 & 900 & 0 & 188 \\
\hline GP7 & $0 \sim 13$ & 20 & 100 & 320 & 80 & 900 & 0 & 188 \\
\hline GP8 & $13 \sim 38$ & 20 & 100 & 320 & 80 & 900 & 0 & 188 \\
\hline GP9 & $38 \sim 75$ & 20 & 100 & 320 & 80 & 900 & 0 & 188 \\
\hline
\end{tabular}

\section{Results and Analysis}

\subsection{Analysis of Potential ASR Hazards of Aggregate}

The 14-day expansion rate of mortar bars of each group is shown in Figure 2. It can be seen from Figure 1 that when glass sand replaces river sand by $20 \%$ and $100 \%$, the 14 -day expansion rate of concrete is $0.179 \%$ and $0.212 \%$, respectively, which is much larger than the critical value of less than $0.1 \%$ required by the code [29]. This shows that there are great safety risks in directly applying waste glass to concrete in the form of glass sand. The necessary ASR suppression treatment must be carried out. Further study found that the expansion rate of concrete mixed with glass powder decreased significantly. For example, the 14-day expansion rate of the sample with a glass powder content of $20 \%$ and a particle size of $13-38 \mu \mathrm{m}$ was only $0.02 \%$, which was much lower than the $0.1 \%$ required by the specification, which indicated that the glass powder could effectively restrain the ASR of concrete, reduce the ASR expansion rate, and improve the service performance of concrete. 
At the same time, when the glass powder content is $20 \%$, and the glass sand content is $100 \%$, the expansion rate of the 14 days concrete is still more than $0.1 \%$. For example, the expansion rate of the sample with a particle size of $13 \mu \mathrm{m}-38 \mu \mathrm{m}$ is $0.129 \%$. Although the expansion rate of the sample without glass powder $(0.212 \%)$ has decreased significantly, there is still a risk of ASR expansion during the service of glass concrete. However, the production cost of glass powder is much higher than that of glass sand, so the application of waste glass in concrete should be combined with glass powder and glass sand according to a certain proportion to achieve the purpose of complementary advantages.

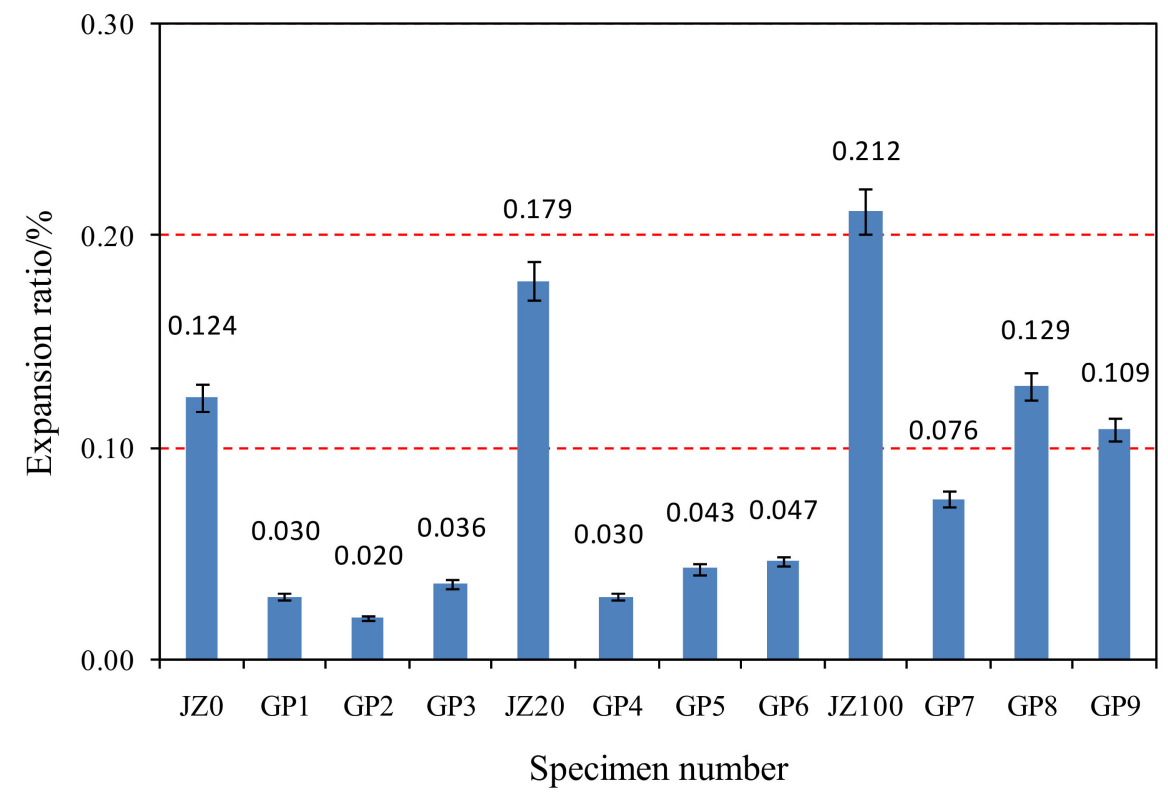

Figure 2. Histogram of 14-day-old expansion rate of mortar rods in each group.

\subsection{SEM Image Analysis of Glass Concrete}

Figure 3 is the SEM image of the specimens with different glass sand content without glass powder during the curing age of 14 days. It can be clearly seen that with the increase of glass sand content, more fluffy and thin-skinned reaction products are generated on the particle surface, and the overall structure is loose and there are many gaps. Based on the appearance characteristics of the reaction product and the energy spectrum analysis of the thin-skinned reaction product in zone A, it is inferred that the reaction product isASR gel. It shows that due to the addition of glass sand, a considerablealkali-silicic acid reaction (ASR) occurred in the composite cementitious material system, resulting in a large amount of ASR gel. These ASR gels will absorb a lot of water and increase their volume, leading to a visible increase in the expansion rate of the sample, shown macroscopically. It is proved that severe ASR occurred in mortar rods without glass powder, and a large number of ASR gels are produced, which will further demonstrate the potential ASR hazard of local river sand in Guilin from the microscopic point of view [24]. 

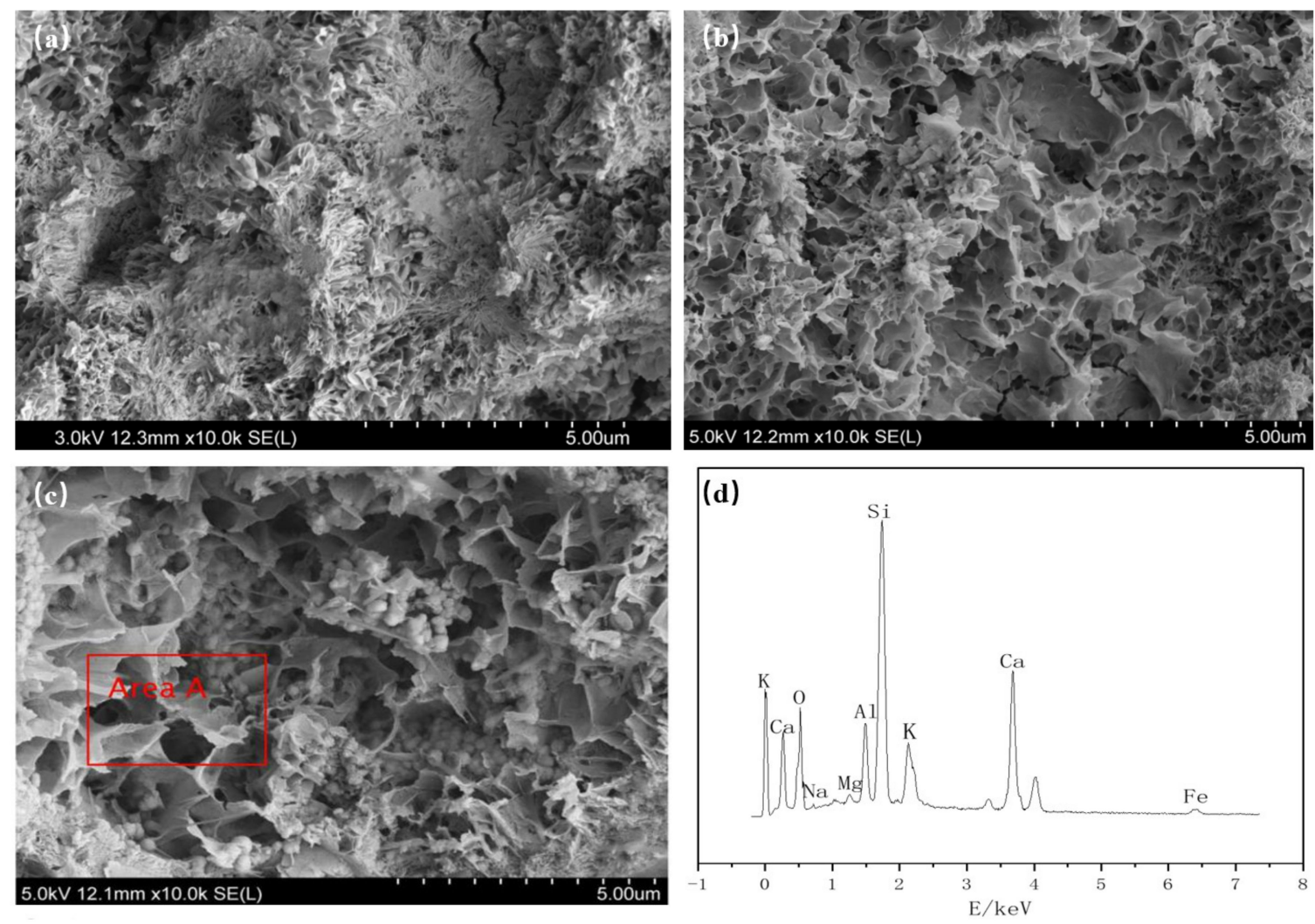

Figure 3. SEM images of 14 dspecimens with different amounts of glass sand content, without glass powder, along with the energy spectrum analysis: (a) JZ0 (glass sand content: 0\%); (b) JZ1 (glass sand content: 20\%); (c) JZ2 (glass sand content: $100 \%) ;(d)$ energy spectrum analysis of area A.

Figure 4 shows the SEM images of specimens with $20 \%$ glass powder and $13-38 \mu \mathrm{m}$ glass powder with different glass sand content for 14 days. It can be seen from Figure $4 a$ that after adding glass powder, a large number of fibrous reaction products are formed on the surface of the concrete particles. These reaction products are closely packed and overlap each other to form a dense structure without a characteristic morphology. It can be judged as CSH gel by the power classification. It is inferred that the glass powder with a smaller particle size can stimulate its potential pozzolanic activity. The composite cementitious material is mainly a denser CSH gel formed by a volcanic ash reaction, which leads to a denser concrete structure and smaller voids. The macroscopic characterization is that the expansion rate of the specimen decreases. At the same time, by comparing the SEM images of GP2/GP5/GP8 and the control group JZ0/JZ1/JZ2, it can be found that when the concrete mix ratio is the same, the amount of loose ASR gel generated on the surface of the GP2/GP5/GP8 concrete particles mixed with glass powder is less, compared with JZ0/JZ1/JZ2 without glass powder, and the surface voids are relatively reduced. It is characterized from the microscopic level that the ground glass powder can effectively inhibit the ASR expansion of the mortar rod specimens. Through the comparison, it is not difficult to find that with the increase inthe amount of glass powder, the loose structure and "paper-like" ASR gel gradually decreases, and the microstructure of the mortar rod becomes increasingly denser, indicating that the reaction products are more CSH gel. The inference in the above experiments is further verified, that is, "the increase in glass powder content will enhance the inhibitory effect on ASR expansion" [43]. 

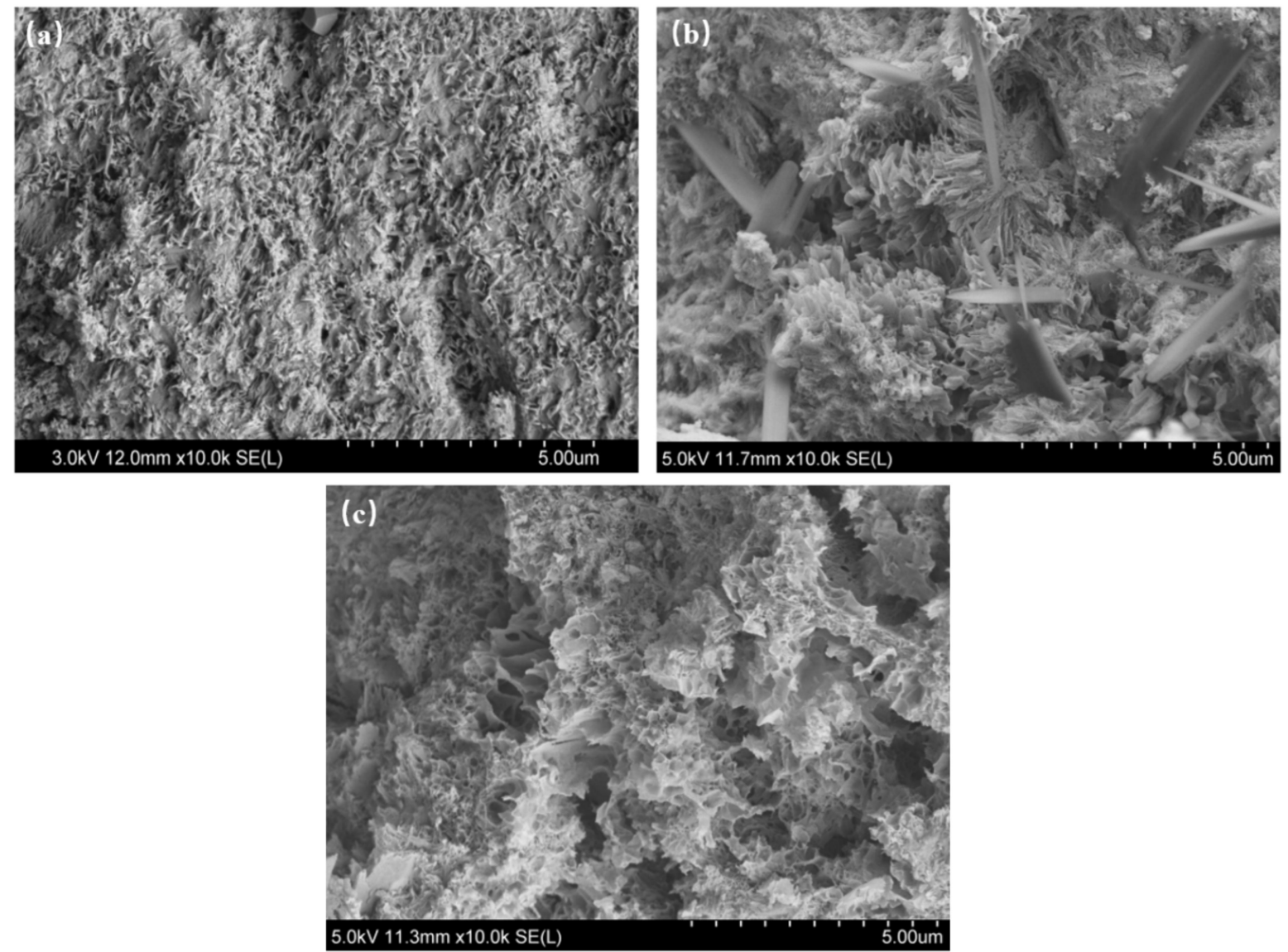

Figure 4. SEM image of different glass sand content specimens with $20 \%$ content and 13-38 $\mu \mathrm{m}$ glass power particle size (14d): (a) GP2 (glass sand content: 0\%); (b) GP5(glass sand content: 20\%); (c) GP8(glass sand content: 100\%).

\subsection{Analysis of the Expansion Mechanism of Glass Concrete ASR}

When the concrete contains reactive aggregate, both favorable pozzolanic reaction and harmful alkali-silica reaction (ASR) may occur. When a pozzolanic reaction occurs in concrete, dense CSH gel is generated, and the reaction formula is shown in Formula (2). When ASR occurs in concrete, loose ASR gel is generated. The ASR reaction formula is similar to the pozzolan reaction formula, but $\mathrm{Na}^{+}$and $\mathrm{K}^{+}$are replaced by $\mathrm{Ca}^{2+}$. The reaction formula is shown in Formula (3). The two reactions coexist and compete with each other.

$$
\begin{gathered}
\mathrm{SiO}_{2}+\mathrm{Ca}^{2+}+2 \mathrm{OH}^{-} \rightarrow n_{1} \mathrm{CaO} \cdot \mathrm{SiO}_{2} \cdot n_{2} \mathrm{H}_{2} \mathrm{O} \\
\mathrm{SiO}_{2}+2 \mathrm{Na}^{+}\left(\mathrm{K}^{+}\right)+2 \mathrm{OH}^{-} \rightarrow \mathrm{Na}_{2}\left(\mathrm{~K}_{2}\right) \cdot \mathrm{SiO}_{3} \cdot \mathrm{H}_{2} \mathrm{O}
\end{gathered}
$$

Combined with the change rule of expansion rate and the comparative analysis of the SEM image, the results indicate that when the glass sand with a larger particle size is mixed into the concrete as fine aggregate, due to the large amount of active $\mathrm{SiO}_{2}$ in the glass sand, it reacts with $\mathrm{OH}^{-}, \mathrm{K}^{+}$, and $\mathrm{Na}^{+}$in the concrete pore solution, resulting in the formation of loose ASR gel; then, the ASR gels are swelled by absorbing water, which increases the expansion rate of the specimen. When the particle size of ground glass is less than a certain value, the potential hydraulic activity and potential pozzolanic property of the glass powder are stimulated, and when used as auxiliary cementing material, the active ingredients in the glass powder such as $\mathrm{SiO}_{2}$ are more involved in the pozzolanic reaction, consuming a large amount of $\mathrm{Ca}(\mathrm{OH})_{2}$ and forming a large amount of dense $\mathrm{CSH}$ gels. On the one hand, because the $\mathrm{OH}^{-}$in the solution is consumed in large quantities, the amount of $\mathrm{OH}^{-}$participating in the ASR is reduced, thus reducing the amount of ASR gels and inhibiting ASR swelling; on the other hand, the generated CSH gels have a strong 
ability to fix $\mathrm{Na}^{+}$[26], which reduces the $\mathrm{Na}^{+}$concentration of pore solution and further reduces the ASR degree of active aggregate.

Therefore, combined with the results of expansion rate and SEM diagram analysis, it is inferred that the inhibition mechanism of glass powder on ASR expansion may be due to the potential pozzolanic property of ground glass powder. When glass powder is mixed into concrete as an auxiliary cementitious material, $\mathrm{SiO}_{2}$ in glass powder is more involved in the pozzolanic reaction, consuming $\mathrm{OH}^{-}$, in solution and reducing ASR rate, thus reducing the formation of ASR gels. It plays a key role in inhibiting the expansion of ASR [7].

\section{Conclusions}

By studying the inhibition effect of waste glass powder on ASR expansion, comparing the expansion rate of concrete specimens with different amounts and particle sizes of glass powder at different ages, the effects of glass powder content and particle size on the inhibition of ASR expansion were analyzed. The ASR expansion effects of glass concrete and its mechanism were studied. The main results are as follows: (1) the main occurrence when usingglass sand is ASR, which produces fluffy ASR gel, leading to the increase inexpansion rate; the expansion rate of concrete increases with the increase of glass sand content, and the 14-day-old expansion rate of mortar bars mixed with glass sand is larger than the standard limit value; therefore, there is a considerable hidden safety danger when waste glass is directly used in concrete in the form of glass sand; (2) the glass powder produces dense $\mathrm{CSH}$ gel by pozzolanic reaction, and the consumption of a large amount of $\mathrm{OH}^{-}$, required by ASR, has a good inhibitory effect on the ASR expansion of concrete, and the inhibitory effect becomes more obvious with the increase in the fineness of the glass powder. The optimum content of glass powder in concrete is less than $20 \%$, and the particle size of glass powder is less than $75 \mu \mathrm{m}$; (3) glasspowder and glass sand can be used in concrete as auxiliary cementitious material and aggregate, respectively, which is beneficial to the recycling of waste glass, but the content of glass sand should not be more than $20 \%$.

Author Contributions: D.H. and P.S. surveyed the detailed literature, data collection, and assisted in drafting the manuscript. Y.W. and G.L. were in charge of the author designed the research work, interpreted the data, and helped in manuscript preparation. P.G. assisted in literature survey, data collection, and drafting the manuscript. X.C. assisted in the experimental investigation and drafting of the manuscript. All authors have read and agreed to the published version of the manuscript.

Funding: National Science Foundation of China (No:51468014) and Guangxi Key Laboratory of New Energy and Building Energy Saving (No:19-J-21-5).

Institutional Review Board Statement: Not applicable.

Informed Consent Statement: Not applicable.

Data Availability Statement: Not applicable.

Conflicts of Interest: The authors declare that they have no conflict of interest.

Availability of Data and Materials: The data and materials are available.

\section{References}

1. Ferdous, W.; Manalo, A.; Siddique, R.; Mendis, P.; Zhuge, Y.; Wong, H.S.; Lokuge, W.; Aravinthan, T.; Schubel, P. Recycling of landfill wastes (tyres, plastics and glass) in construction-A review on global waste generation, performance, application and future opportunities. Resour. Conserv. Recycl. 2021, 173, 105745. [CrossRef]

2. Dong, W.; Guo, Y.; Sun, Z.; Tao, Z.; Li, W. Development of self-sensing cement-based sensor using recycled fine waste glass aggregates coated with carbon nanotube. J. Clean. Prod. 2021, 314, 127968. [CrossRef]

3. Silva, R.V.; De Brito, J.; Dhir, R.K. Properties and composition of recycled aggregates from construction and demolition waste suitable for concrete production. Constr. Build. Mater. 2014, 65, 201-217. [CrossRef]

4. Nodehi, M.; Taghvaee, V.M. Sustainable concrete for circular economy: A review on use of waste glass. Glass Struct. Eng. 2021, 1-20. [CrossRef] 
5. Sangha, C.M.; Alani, A.M.; Walden, P.J. Relative strength of green glass cullet concrete. Mag. Concr. Res. $2004,56,293-297$. [CrossRef]

6. Memon, S.A. Phase change materials integrated in building walls: A state of the art review. Renew. Sustain. Energy Rev. 2014, 31, 870-906. [CrossRef]

7. Shi, C.; Zheng, K. A review on the use of waste glasses in the production of cement and concrete. Resour. Conserv. Recycl. 2007, 52, 234-247. [CrossRef]

8. Soroushian, P. Strength and durability of recycled aggregate concrete containing milled glass as partial replacement for cement. Constr. Build. Mater. 2012, 29, 368-377.

9. Nodehi, M.; Taghvaee, V.M. Alkali-activated materials and geopolymer: A review of common precursors and activators addressing circular economy. Circ. Econ. Sustain. 2021, 1-32. [CrossRef]

10. Naganna, S.R.; Ibrahim, H.A.; Yap, S.P.; Tan, C.G.; Mo, K.H.; El-Shafie, A. Insights into the Multifaceted Applications of Architectural Concrete: A State-of-the-Art Review. Arab. J. Sci. Eng. 2021, 46, 4213-4223. [CrossRef]

11. De Brito, J.; Kurda, R. The past and future of sustainable concrete: A critical review and new strategies on cement-based materials. J. Clean. Prod. 2021, 281, 123558. [CrossRef]

12. Lu, J.-X.; Shen, P.; Zheng, H.; Zhan, B.; Ali, H.A.; He, P.; Poon, C.S. Synergetic recycling of waste glass and recycled aggregates in cement mortars: Physical, durability and microstructure performance. Cem. Concr. Compos. 2020, 113, 103632. [CrossRef]

13. Ahmad, W.; Khan, M.; Smarzewski, P. Effect of Short Fiber Reinforcements on Fracture Performance of Cement-Based Materials: A Systematic Review Approach. Materials 2021, 14, 1745. [CrossRef]

14. Omoding, N.; Cunningham, L.S.; Lane-Serff, G.F. Effect of using recycled waste glass coarse aggregates on the hydrodynamic abrasion resistance of concrete. Constr. Build. Mater. 2021, 268, 121177. [CrossRef]

15. Khan, M.N.N.; Saha, A.K.; Sarker, P.K. Reuse of waste glass as a supplementary binder and aggregate for sustainable cement-based construction materials: A review. J. Build. Eng. 2020, 28, 101052. [CrossRef]

16. Mohajerani, A.; Vajna, J.; Cheung, T.H.H.; Kurmus, H.; Arulrajah, A.; Horpibulsuk, S. Practical recycling applications of crushed waste glass in construction materials: A review. Constr. Build. Mater. 2017, 156, 443-467. [CrossRef]

17. Jayakumar, G.; Mathews, M.E.; Kiran, T.; Yadav, B.S.K.; Kanagaraj, B.; Anand, N. Development and strength assessment of sustainable high strength fiber reinforced concrete. Mater. Today Proc. 2021. [CrossRef]

18. Wang, H.Y.; Huang, W.L. Durability of self-consolidating concrete using waste LCD glass. Constr. Build. Mater. 2010, $24,1008-1013$. [CrossRef]

19. Meyer, C.; Baxter, S.; Jin, W. Potential of waste glass for concrete masonary blocks. In Materials for the New Millennium, Proceedings of the 4th Materials Engineering Conference, Washington, DC, USA, 10-14 November 1996; American Society of Civil Engineers: New York, NY, USA, 1996; pp. 666-673.

20. Jani, Y.; Hogland, W. Waste glass in the production of cement and concrete-A review. J. Environ. Chem. Eng. 2014, 2, 1767-1775. [CrossRef]

21. Jochem, L.F.; Casagrande, C.A.; Onghero, L.; Venâncio, C.; Gleize, P.J. Effect of partial replacement of the cement by glass waste on cementitious pastes. Constr. Build. Mater. 2021, 273, 121704. [CrossRef]

22. Omran, A.F.; D.-Morin, E.; Harbec, D.; Tagnit-Hamou, A. Long-term performance of glass-powder concrete in large-scale field applications. Constr. Build. Mater. 2017, 135, 43-58. [CrossRef]

23. Xie, G.G.; Kong, Y.N.; Liu, S.H. Research progress on ASR of glass concrete. Adv. Mater. Ind. 2012, 7, 65-71.

24. Jin, W.H.; Meyer, C.; Baxter, S. "Glascrete" —Concrete with glass aggregate. ACI Mater. J. 2000, 97, $208-213$.

25. Bazant, Z.P.; Zi, G.; Meyer, C. Fracture mechanics of ASR in concretes with waste glass particles of different sizes. Eng. Mech. ASCE 2000, 126, 226-232. [CrossRef]

26. Taha, B.; Nounu, G. Utilizing waste recycled glass as sand/cement replacement in concrete. J. Mater. Civ. Eng. 2009, 21, 709-721. [CrossRef]

27. Lee, G.; Ling, T.-C.; Wong, Y.-L.; Poon, C.-S. Effects of crushed glass cullet sizes, casting methods and pozzolanic materials on ASR of concrete blocks. Constr. Build. Mater. 2011, 25, 2611-2618. [CrossRef]

28. Li, F.H.; Zhang, G.B.; Zhou, H.Y.; Li, G. Inhibition Effect of Super Metakaolin and Fly Ash on Alkali-Silica Reaction in Concrete. J. Build. Mater. 2017, 20, 876-880.

29. Zhao, Y.; Sun, P.; Chen, P.; Guan, X.; Wang, Y.; Liu, R.; Wei, J. Component Modification of Basic Oxygen Furnace Slag with C4AF as Target Mineral and Application. Sustainability 2021, 13, 6536. [CrossRef]

30. Ming, Y.; Chen, P.; Wang, Y.; Li, L.; Chen, X.; Sun, P. Experimental Research of Concrete with Steel Slag Powder and Zeolite Powder. J. Renew. Mater. 2020, 8, 1647-1655. [CrossRef]

31. Leemann, A.; Lörtscher, L.; Bernard, L.; LE Saout, G.; Lothenbach, B.; Espinosa-Marzal, R.M. Mitigation of ASR by the use of LiNO3-Characterization of the reaction products. Cem. Concr. Res. 2014, 59, 73-86. [CrossRef]

32. Tremblay, C.; Bérubé, M.A.; Fournier, B.; Thomas, M.D.; Folliard, K.J. Experimental investigation of the mechanisms by which LiNO3 is effective against ASR. Cem. Concr. Res. 2010, 40, 583-597. [CrossRef]

33. Liu, J.; Yu, L.; Deng, M. Effect of LiNO3 on Expansion of Alkali-Silica Reaction in Rock Prisms and Concrete Microbars Prepared by Sandstone. Materials 2019, 12, 1150. [CrossRef]

34. Shi, Z.; Ma, B.; Lothenbach, B. Effect of $\mathrm{Al}$ on the formation and structure of alkali-silica reaction products. Cem. Concr. Res. 2021, 140, 106311. [CrossRef] 
35. Yang, L.R.; Feng, X.X.; Liu, G. Investigation on the suppressing effect of $\mathrm{Al}^{3+}$ on expansion due to alkali-Silica reaction. Concrete 2010, 5, 35-38.

36. Rajabipour, F.; Maraghechi, H.; Fischer, G. Investigating the alkali-silica reaction of recycled glass aggregates in concrete materials. J. Mater. Civ. Eng. 2010, 22, 1201-1208. [CrossRef]

37. Suwito, A.; Jin, W.H.; Xi, Y.; Meyer, C. A mathematical model for the pessimum size effect of ASR in concrete. Concr. Sci. Eng. 2002, 4, 23-34.

38. Dyer, T.D.; Dhir, R.K. Chemical Reactions of Glass Cullet Used as Cement Component. J. Mater. Civ. Eng. 2001, 13, 412-417. [CrossRef]

39. Shi, C.; Wu, Y.; Riefler, C.; Wang, H. Characteristics and pozzolanic reactivity of glass powders. Cem. Concr. Res. 2005, 35, 987-993. [CrossRef]

40. Zheng, K.R.; Chen, L.; Zhou, J. Pozzolanic Reaction of Soda-lime Glass and Its Influences on Composition of Calcium Silicate Hydrate. J. Chin. Ceram. Soc. 2016, 44, 202-210. [CrossRef]

41. Liu, S.; Wang, S.; Tang, W.; Hu, N.; Wei, J. Inhibitory Effect of Waste Glass Powder on ASR Expansion Induced by Waste Glass Aggregate. Materials 2015, 8, 6849-6862. [CrossRef]

42. Ming, Y.; Sun, P.; Chen, P. Experimental research on preparation of high strength concrete with rice husk ash instead of silica fume. E3S Web Conf. EDP Sci. 2021, 233, 01053. [CrossRef]

43. Shayan, A.; Xu, A. Value-added utilisation of waste glass in concrete. Cem. Concr. Res. 2004, 34, 81-89. [CrossRef] 